\title{
Predictors of communication preferences in patients with chronic low back pain
}

\author{
This article was published in the following Dove Press journal: \\ Patient Preference and Adherence \\ 22 October 2013 \\ Number of times this article has been viewed
}

\section{Erik Farin \\ Lukas Gramm \\ Erika Schmidt \\ University Freiburg, Medical Center, Department of Quality Management and Social Medicine, Freiburg, Germany}

Correspondence: Erik Farin University Freiburg Medical Center, Department of Quality Management and Social Medicine, Engelbergerstrasse 2I, D-79106 Freiburg, Germany

$\mathrm{Fax}+4976 \quad 127073310$

Tel +4976I 27074430

Email erik.farin@uniklinik-freiburg.de
Background: The objective of this exploratory study was to identify patient-related predictors of communication preferences in patients with chronic low back pain for various dimensions of patient-physician communication (patient participation and orientation, effective and open communication, emotionally supportive communication, communication about personal circumstances).

Methods: Eleven rehabilitation centers from various parts of Germany participated in collection of data between 2009 and 2011. A total of 701 patients with chronic low back pain were surveyed at the start of rehabilitation. The patient questionnaire captured communication preferences, pain impact, pain intensity, and psychologic variables (fear avoidance beliefs, illness coherence, control beliefs, communication self-efficacy, and personality characteristics). The rehabilitation physicians filled out a documentation sheet containing information on diagnosis, inability to work, duration of the illness, and comorbidity at the beginning and end of rehabilitation. Hierarchical regression analyses were performed.

Results: On average, effective, open, and patient-centered communication was very important for patients with back pain, emotionally supportive communication was important, and communication about personal circumstances was somewhat important. The variance in communication preferences explained by the predictors studied here was $8 \%-19 \%$. Older patients showed a lower preference for patient-centered and open communication, but a higher preference for communication about personal circumstances. Patients with psychologic risk factors (eg, fear avoidance beliefs), extroverted patients, and patients with high self-efficacy in patient-physician interaction generally had higher expectations of the physician's communicative behavior.

Conclusion: Providers should take into consideration the fact that patients with back pain have a strong need for effective, open, and patient-centered communication. A flexible approach to communication needs appears to be especially important for communication about emotional and personal circumstances, because the patients differ most clearly in this respect. Personal characteristics provided only initial clues to possible preferences; for more precision, an individual assessment (by means of questionnaires or discussion) is needed.

Keywords: patient-physician relationship, patient-physician communication, preferences, low back pain, rehabilitation

\section{Introduction}

In the treatment of chronically ill patients, which is marked by a long treatment period, a biopsychosocial disease model, promotion of self-management competency and health behavior, and good communication between patient and provider is important for promoting successful treatment. ${ }^{1-3}$ For patients with chronic low back pain (CLBP), patient-provider communication is particularly relevant, as pain must 
be identified as a subjective phenomenon in the discussion ${ }^{4}$ and the patient-provider relationship is often difficult and conflict-laden in this patient population..$^{5-8}$

Existing studies show that there are sometimes clear differences among patients regarding expectations of communication with the provider. This applies to participation in decision-making processes ("shared decision-making"), and also to other dimensions of communication, such as conveying illness-related information, addressing psychosocial problems, and providing emotionally supportive communication. ${ }^{9}{ }^{10}$ In addition, the preferences may vary in one and the same patient depending on context and progress over time. For instance, patients may desire patient-centered communication in principle, but when they become seriously ill or when their therapist emphasizes the ambiguity and uncertainty of certain treatments, they then tend to prefer a directive communication style. ${ }^{11}$ Mallinger et al ${ }^{12}$ demonstrated in cancer patients that the preference for involvement in medical decision-making is not static, and in most patients varies over the course of treatment.

However, addressing the patient's respective expectations can be considered a central aspect of patient-centered care. ${ }^{13}$ The patient's communication-related preferences are among the factors that decide which provider behavior is assessed as positive or negative; these are moderators of the relationship between provider communication behavior and desired endpoints, such as adherence, satisfaction with treatment, and health behavior. ${ }^{14}$ Studies that explicitly analyze the congruence between patient and provider come to the rather uniform conclusion that congruence is associated with positive effects. Jahng et $\mathrm{a}^{15}$ found that patient outcomes (patient satisfaction, patient adherence, patient health perception) tend to be more positive when patients and their doctors share similar beliefs about patient participation. Cvengros et $\mathrm{a}^{16}$ came to similar conclusions regarding the congruence between patient preferences of clinical encounters and reports of analogous dimensions of provider behavior. Street et $\mathrm{a}{ }^{17}$ reported that the physician-patient relationship is strengthened when patients see themselves as similar to their physicians in terms of their personal beliefs, values, and communication. They examined ratings of trust, satisfaction, and intention to adhere as outcomes.

There has thus been a call to focus research more on the aspect of "patient-physician fit"18 and to train the provider to react flexibly to the patient's communication needs. Rodin et a ${ }^{19}$ recommend that providers individualize their communication style, given that patients' communication preferences often differ. Other reviews and primary studies with large numbers of cases have had comparable results. ${ }^{20-22}$ One fundamental prerequisite for individualizing the communication style is that the provider must be aware of the patient's communication preferences. However, providers are generally unable to estimate the patient's preferences and opinions correctly according to their clinical impression. Hall et $\mathrm{al}^{23}$ examined primary care physicians' awareness of their patients' opinions of the quality of communication and found no relationship between patients' perceptions and physicians' perceptions. Sobo ${ }^{24}$ found that two thirds of nurses misjudged parents' communication preferences. This is presumably attributable to the fact that it is not easy to identify the patient's communication preferences by simply observing their communication behavior, as Hudak et $\mathrm{al}^{25}$ show.

Consequently, either assessment instruments (eg, patient questionnaires ${ }^{26-28}$ ) should be used for measuring communication preferences or the patient should be asked directly during the discussion about his/her expectations. Both methods are time-consuming and could be made easier by knowledge of possible patient-related predictors (eg, sex, age) of communication preferences. For example, if it were known that elderly persons particularly value emotionally supportive communication, special sensitivity to emotional communication could be shown for this patient group and patients could be asked specifically about their preferences for this aspect.

Irrespective of the practical relevance, knowledge of patient-related factors that influence communication preferences is also relevant from the perspective of basic research, because little is known about how communication preferences are formed and how they relate to other psychologic characteristics of the patient. A summary of existing research results reveals quite consistent results regarding preference for a participatory communication style: persons who want to be involved in treatment planning and therapy decisions tend to be young, educated, and female. ${ }^{29-32}$ However, the percentage of variance in communication preferences that is explained by patient-related predictors is generally quite low (eg, 14\% in Garfield et a $\mathrm{a}^{33}$ ). Therefore, reliable prediction of the communication preferences of patients is hardly possible using basic patient characteristics alone.

Existing research on predictors of communication preferences focuses intensely on a patient-centered, participatory communication style; there are far fewer findings concerning other aspects of communication that may be even more important for patients (eg, emotional support). ${ }^{34,35}$ In addition, the authors are not aware of any study that specifically examines CLBP patients. Mixed patient samples from general 
medical practices or oncology units have often been surveyed. The objective of this exploratory study was to identify patient-related predictors of communication preferences for CLBP patients and for various dimensions of patient-provider communication. In order to determine the influence of these patient-related predictors as completely as possible, medical variables (eg, chronification), pain impact variables (eg, pain intensity, disability), and psychologic variables (eg, extraversion, self-efficacy) were taken into consideration, along with sociodemographic variables. Our study is a continuation of previous investigations undertaken while designing a new questionnaire about communication preferences ${ }^{26}$ and analyzing the match between patient communication preferences and physician communication behavior. ${ }^{36}$

Our hypothesis is practically relevant because understanding significant patient-related predictors of communication preferences would enable us to predict patients' expectations. If predictors were readily observable (ie, age, sex) or easy to assess (ie, pain intensity, chronification), providers could make an initial judgment as to a patient's probable communication preferences without much difficulty, and adapt their communicative behavior accordingly. This would, however, require that the predictors explain a substantial amount of variance. Our hypothesis is also relevant to research on patient-centeredness, because hypotheses regarding how preferences are constructed can be derived from knowledge about the predictors of patient communication preferences. The development of patient preferences is an important research field that may well attract more attention in the future. ${ }^{37}$

\section{Materials and methods}

\section{Sample and design}

The study was approved by the ethics committee at University Freiburg (approval number 62/08). Eleven rehabilitation centers from various parts of Germany participated in the collection of data between 2009 and 2011. This is an ad hoc sample of centers that expressed interest in this research subject. Patients with chronic low back pain were surveyed. The criterion for inclusion in our study was chronic low back pain for at least 6 months. We informed the centers that the study patients should have been diagnosed according to the International Classification of Diseases (ICD) categories M47.1-M47.9, M48.1, M48.2, M48.8, M48.9, M51.0-M51.9, M53.8, M53.9, M54.1, M54.3, M54.4, M54.5, M54.8, M54.9, and F45.4. The patient questionnaires were given only to patients who were able and willing to complete the questionnaires (informed consent). Patients with specific low back pain due to tumors or inflammatory disease were not included.
At the beginning of rehabilitation (ie, within the first 3 days of what is generally a 3 -week rehabilitation program), the patients were asked to fill out the questionnaires. They were asked to do this on their own, in their room or in the lounge. The rehabilitation physicians filled out a documentation sheet at the beginning and end of rehabilitation (usually after the patient's examinations on admission and discharge). The documentation sheet contained information concerning diagnosis, inability to work, duration of illness, and comorbidity. We applied these data as sociodemographic or medical predictors of communication preferences (see following section).

\section{Instruments}

Sociodemographic patient characteristics (age, sex, regular partner, highest level of education completed, employment, income, inability to work) were recorded using patient or physician information. Medical variables considered were duration of the illness, treatment motivation assessed by the physician on a 6-point rating scale where 1 indicates no motivation and 6 indicates very high motivation, and comorbidity (measured using a rehabilitation-specific comorbidity score). ${ }^{38}$ To assess pain impact, pain intensity (visual analog scale, range 0-100), and disability (Oswestry Disability Index [ODI], German version) ${ }^{39}$ were measured. Additionally, various psychologic variables were measured that are assumed to have an effect on the patient's communication preferences, ie, the personality characteristics of warmth and gregariousness (measured using the facet scales of the same name in the NEO Personality Inventory, German version), ${ }^{40}$ fear avoidance beliefs (Fear Avoidance Beliefs Questionnaire, German version), ${ }^{41}$ illness coherence (Illness Coherence scale IPQ-COH of the Revised Illness Perception Questionnaire, ${ }^{42}$ German version, ${ }^{43}$ reliability in our sample Cronbach's alpha $=0.83$ ), and the Control Beliefs Concerning Illness and Health questionnaire. ${ }^{44}$ The latter is a widely used instrument in Germany and measures the general health-related locus of control. The three scales, each of which includes seven items, measure internal locus of control (reliability in our sample Cronbach's alpha $=0.83$ ), social external locus of control (Cronbach's alpha $=0.68$ ), and fatalistic external locus of control (Cronbach's alpha $=0.79$ ).

Further, a German version of the Perceived Efficacy in Patient-Physician Interactions ${ }^{45}$ was used. This instrument measures patients' self-efficacy in obtaining medical information and attention to their medical concerns from physicians (reliability in our sample Cronbach's alpha $=0.91)$. 
The recently developed KOPRA questionnaire ${ }^{26}$ was used to measure the communication preferences of patients. This instrument comprises four scales (ie, patient participation and patient orientation, effective and open communication, emotionally supportive communication, and communication about personal circumstances) that are unidimensional, fulfill the demands for a one-parameter item response theory model, and are reliable (Cronbach's alpha 0.80-0.92). The patient participation and patient orientation scale (11 items) measures patient communication preferences with respect to the patient's participation in treatment and consideration of their opinions and preferences. One typical item is "...weigh the advantages and disadvantages of different treatment options with you" (response categories: 1, not so important; 2, somewhat important; 3, important; 4, very important; 5, extremely important). The effective and open communication scale (10 items) measures preferences with respect to effectively collecting, conveying, and sharing information and open communication about negative events (eg, "listen carefully when you want to say something" and “... always tell you everything about your illness, even if it is unpleasant"). The emotionally supportive communication scale (six items) measures preferences regarding emotionally supportive communication (eg, "give you encouragement during talks" and "always be optimistic and upbeat during talks with you"). The communication about personal circumstances scale (five items) measures preferences regarding a personal communication style that also includes private aspects (eg, "occasionally talk to you about private matters" and "sometimes talk with you about things that have nothing to do with your illness"). The KOPRA questionnaire, depending on instructions, can be applied to different occupational groups. In our study, the patients were asked to apply it to communication preferences with respect to the physician in the pending rehabilitation.

\section{Analyses}

Hierarchical regression analyses were performed, in which all sociodemographic variables listed in the Instruments section were included first. In the second block, all medical variables listed in the Instruments section were added, and in the third block pain impact variables were added. Finally, in the fourth block, the psychologic characteristics were included. Since we conduct regression analyses with a large number of predictors, multiple imputation ${ }^{46}$ was used. Five imputed data sets were created using NORM software ${ }^{47}$ according to the recommendations of Rubin. ${ }^{48}$ The relevant parameters were combined according to the rules presented by Rubin. ${ }^{48}$
A stepwise method of variable inclusion (probability for inclusion $=0.05$, probability of removing a variable from the regression equation $=0.10$ ) was employed. The predictors that were included in the model in at least two of the five imputed data sets were considered as potentially relevant predictors. With this restriction, more sparse models could be specified and problems of multicollinearity avoided. A separate model was specified for each of the four KOPRA scales. Finally, the regression models that consisted only of potentially relevant predictors were again applied to all five imputed sets. Here again, hierarchical regression analyses were computed, but now using the forced entry method of variable inclusion, making the results in the five imputed data sets directly comparable. For the diagnosis of multicollinearity, the variance inflation factor was calculated. Values over 5 can be considered as an indication of multicollinearity. ${ }^{49}$ Statistical analyses were performed using Statistical Package for the Social Sciences version 19 software (IBM Corporation, Armonk, NY, USA) ${ }^{49}$

\section{Results}

A total of 1039 patients were asked to participate, and 701 agreed. The percentage of patients who did not fill out the questionnaire (decliners) was $32.5 \%$. The most important reason for noninclusion was refusal to participate $(n=210)$, followed by language problems $(n=54)$ and cognitive or physical limitations $(\mathrm{n}=22)$. No reason for noninclusion was reported for 52 of the patients. According to the patients, the average amount of time they needed to fill out the questionnaire was $49 \pm 33$ minutes. Table 1 provides information on the patients in the study.

The results of the regression analyses are shown in Table 2. In order to be able to interpret the results bet-

Table I Respondent characteristics

\begin{tabular}{ll}
\hline Age, years (mean \pm SD) & $51.0 \pm 11.2$ \\
Sex & \\
$\quad$ Percent female & 57.2 \\
Level of education (highest level completed) & \\
$\quad$ Percent elementary school & 31.5 \\
Employment & \\
$\quad$ Percent employed & 72.3 \\
ODI (0-100, mean \pm SD) & $31.1 \pm 15.9$ \\
Pain intensity (VAS 0-100, mean \pm SD) & $52.9 \pm 22.7$ \\
Chronification (\%) & \\
$\quad<$ I year & 13.0 \\
I-2 years & 11.1 \\
3-5 years & 18.6 \\
6-I0 years & 16.3 \\
$>10$ years & 40.2 \\
\hline
\end{tabular}

Abbreviations: SD, standard deviation; ODI, Oswestry Disability Index; VAS, visual analog scale. 
ter, Table 3 presents the bivariate correlations between predictors and communication preferences and Table 4 presents the intercorrelations among the significant predictors. Multicollinearity was low in the regression analyses; the variance inflation factor value was always under 2.0 and usually ranged between 1.1 and 1.3. The explanation of variance by sociodemographic variables alone was low, and depending on the scale, ranged between $0.8 \%$ and $3.2 \%$ (see Table 2). The only significant predictor was age. Older CLBP patients had less preference for a patient-centered, participatory communication style and preferred open and clear communication. However, for them, communication about personal circumstances was more important than for younger patients. This age effect, as the rather low explanation of variance shows, was not very large. Table 5 shows the effect by presenting the KOPRA scale values for three different age groups.

The medical predictors were not significant. However, impact of pain led to an increase in explained variance from
$1.7 \%$ to $2.7 \%$. Greater intensity of pain was associated with more pronounced communication needs on all scales.

The psychologic variables, which were not included until the last step, led to the greatest increase in variance, which was between $3.9 \%$ and $16.0 \%$. More pronounced fear avoidance beliefs and an external locus of control were associated with more pronounced communication needs on many scales. As can be expected, all areas of communication (except patient-centered communication) were more important for patients who had higher values for warmth as a personality characteristic. Unexpectedly, gregariousness was negatively associated with the preference for emotionally supportive communication. However, this relationship was just barely significant. Perceived efficacy in patient-physician interaction was the one predictor that was most consistently related to all areas of communication. As expected, persons with greater communication self-efficacy also had higher expectations of patient-physician communication. Overall, between $8.2 \%$ and $18.6 \%$ of the variance in communication

Table 2 Hierarchical regression analyses to predict communication preferences

\begin{tabular}{|c|c|c|c|c|}
\hline & $\begin{array}{l}\text { Patient participation } \\
\text { and patient orientation }\end{array}$ & $\begin{array}{l}\text { Effective and open } \\
\text { communication }\end{array}$ & $\begin{array}{l}\text { Emotionally supportive } \\
\text { communication }\end{array}$ & $\begin{array}{l}\text { Communication about } \\
\text { personal circumstances }\end{array}$ \\
\hline \multicolumn{5}{|l|}{ Block I } \\
\hline \multicolumn{5}{|l|}{ Sociodemographic variables } \\
\hline Age & $-0.160(P=0.002)$ & $-0.269(P<0.001)$ & - & $0.212(P=0.009)$ \\
\hline Income & - & - & $-0.762(P=0.100)$ & - \\
\hline$R^{2}$ change after block I & $0.008(P=0.021)$ & $0.032(P<0.001)$ & $0.006(P=0.067)$ & $0.018(P=0.001)$ \\
\hline \multicolumn{5}{|l|}{ Block 2} \\
\hline \multicolumn{5}{|l|}{ Medical variables } \\
\hline Chronification $3-10$ years & - & - & $3.24 \mid(P=0.054)$ & - \\
\hline$R^{2}$ change after block 2 & & & $0.010(P=0.014)$ & \\
\hline \multicolumn{5}{|l|}{ Block 3} \\
\hline \multicolumn{5}{|l|}{ Pain impact variables } \\
\hline Pain intensity (VAS) & $0.066(P=0.01 \mathrm{I})$ & $0.082(P=0.003)$ & $0.143(P=0.002)$ & $0.043(P=0.293)$ \\
\hline ODI & - & - & $-0.201(P=0.005$ & - \\
\hline$R^{2}$ change after block 3 & $0.017(P=0.001)$ & $0.027(P<0.001)$ & $0.020(P=0.003)$ & $0.007(P=0.034)$ \\
\hline \multicolumn{5}{|l|}{ Block 4} \\
\hline \multicolumn{5}{|l|}{ Psychological variables } \\
\hline FABQ: work beliefs & - & $1.069(P=0.008)$ & - & $1.260(P=0.034)$ \\
\hline FABQ: activity beliefs & $0.950(P=0.017)$ & - & $1.199(P=0.035)$ & - \\
\hline $\begin{array}{l}\text { Social external locus } \\
\text { of control }\end{array}$ & $0.346(P=0.004)$ & $0.308(P=0.012)$ & $0.552(P=0.00 \mathrm{I})$ & - \\
\hline $\begin{array}{l}\text { Fatalistic external locus } \\
\text { of control }\end{array}$ & - & - & $0.398(P=0.009)$ & $0.675(P<0.00 I)$ \\
\hline NEO: warmth & - & $0.234(P=0.020)$ & $0.503(P=0.00 \mathrm{I})$ & $0.394(P=0.010)$ \\
\hline NEO: gregariousness & - & - & $-0.309(P=0.049)$ & - \\
\hline PEPPI & $0.210(P<0.001)$ & $0.129(P=0.035)$ & $0.328(P<0.00 \mathrm{I})$ & $0.0305(P=0.00 \mathrm{I})$ \\
\hline$R^{2}$ change after block 4 & $0.160(P<0.001)$ & $0.039(P<0.001)$ & $0.088(P<0.00 \mathrm{I})$ & $0.057(P<0.001)$ \\
\hline$R^{2}$ (final model) & $0.186(P<0.001)$ & $0.098(P<0.001)$ & $0.123(P<0.001)$ & $0.082(P<0.00 I)$ \\
\hline
\end{tabular}

Notes: Unstandardized regression coefficients and $R^{2}$ change with significance. - , not in the model. Significant parameters $(P<0.05)$ are printed in bold type. Only significant predictors were shown.

Abbreviations: FABQ, Fear Avoidance Beliefs Questionnaire; PEPPI, Perceived Efficacy in Patient-Physician Interactions; ODI, Oswestry Disability Index; VAS, visual analog score; NEO, Neuroticism-Extroversion-Openness Inventory. 
Table 3 Correlations between predictors and communication preferences

\begin{tabular}{|c|c|c|c|c|}
\hline & $\begin{array}{l}\text { Patient participation } \\
\text { and patient orientation }\end{array}$ & $\begin{array}{l}\text { Effective and open } \\
\text { communication }\end{array}$ & $\begin{array}{l}\text { Emotionally supportive } \\
\text { communication }\end{array}$ & $\begin{array}{l}\text { Communication about } \\
\text { personal circumstances }\end{array}$ \\
\hline Age & $\begin{array}{l}-0.084 \\
(P=0.028)\end{array}$ & $\begin{array}{l}-0.189 \\
(P<0.001)\end{array}$ & NS & $\begin{array}{l}0.136 \\
(P<0.001)\end{array}$ \\
\hline Pain intensity (VAS) & $\begin{array}{l}0.117 \\
(P=0.003)\end{array}$ & $\begin{array}{l}0.15 \mathrm{I} \\
(P<0.00 \mathrm{I})\end{array}$ & $\begin{array}{l}0.089 \\
(P=0.022)\end{array}$ & $\begin{array}{l}0.083 \\
(P=0.032)\end{array}$ \\
\hline ODI & $\begin{array}{l}0.115 \\
(P=0.004)\end{array}$ & $\begin{array}{l}0.116 \\
(P=0.003)\end{array}$ & NS & NS \\
\hline FABQ: work beliefs & $\begin{array}{l}0.120 \\
(P=0.002)\end{array}$ & $\begin{array}{l}0.166 \\
(P<0.001)\end{array}$ & $\begin{array}{l}0.107 \\
(P=0.007)\end{array}$ & $\begin{array}{l}0.099 \\
(P=0.012)\end{array}$ \\
\hline FABQ: activity beliefs & $\begin{array}{l}0.133 \\
(P=0.001)\end{array}$ & $\begin{array}{l}0.106 \\
(P=0.007)\end{array}$ & $\begin{array}{l}0.130 \\
(P=0.001)\end{array}$ & NS \\
\hline Social external locus of control & $\begin{array}{l}0.124 \\
(P=0.00 I)\end{array}$ & $\begin{array}{l}0.112 \\
(P=0.004)\end{array}$ & $\begin{array}{l}0.167 \\
(P<0.00 I)\end{array}$ & $\begin{array}{l}132 \\
(P=0.001)\end{array}$ \\
\hline Fatalistic external locus of control & NS & NS & $\begin{array}{l}0.146 \\
(P<0.00 I)\end{array}$ & $\begin{array}{l}0.183 \\
(P<0.001)\end{array}$ \\
\hline NEO: warmth & NS & NS & $\begin{array}{l}0.117 \\
(P=0.002)\end{array}$ & $\begin{array}{l}0.096 \\
(P=0.012)\end{array}$ \\
\hline NEO: gregariousness & NS & NS & NS & NS \\
\hline PEPPI & $\begin{array}{l}0.135 \\
(P<0.00 \mathrm{I})\end{array}$ & $\begin{array}{l}0.090 \\
(P=0.020)\end{array}$ & $\begin{array}{l}0.15 \mathrm{I} \\
(P<0.00 \mathrm{I})\end{array}$ & $\begin{array}{l}0.098 \\
(P=0.011)\end{array}$ \\
\hline
\end{tabular}

Notes: Correlation coefficients with significance; only significant parameters $(P<0.05)$ are shown.

Abbreviations: FABQ, Fear Avoidance Beliefs Questionnaire; NS, not significant; PEPPI, Perceived Efficacy in Patient-Physician Interactions; ODI, Oswestry Disability Index; VAS, visual analog score; NEO, Neuroticism-Extroversion-Openness Inventory.

preferences was explained. The most variance was explained for the preference for a patient-centered communication style and the least for the preference for communication about personal circumstances. In line with the low explained variance are the low bivariate correlations between predictors and communication preferences (Table 3 ). The maximum correlation was $r=0.183$.

It is surprising that disability as measured by the ODI was (in contrast with pain intensity) negatively associated with the emotionally supportive communication scale, although disability and pain intensity correlated highly positively $(r=0.658$, see Table 4). We interpret this phenomenon as a suppression effect. ${ }^{50}$ According to Conger, ${ }^{51}$ a suppressor variable is a variable "which increases the predictive validity of another variable (or set of variables) by its inclusion in a regression equation". We tested this and were able to show that this condition for the ODI variable regarding pain intensity is fulfilled in prediction of the emotionally supportive communication KOPRA scale. The regression weight of pain intensity is clearly lower and loses its significance when the ODI variable is taken out of the model. Further, the unexpected significance of the ODI variables disappears when pain intensity is taken out of the model (see Table 3, which shows no bivariate correlation in the unexpected direction for the ODI variable with respect to the emotionally supportive communication scale). Therefore, it can be assumed that greater disability, mediated by pain, contributes to greater communication needs in the emotional area. Simultaneously, disability adjusted for pain intensity is associated with a lower preference for emotionally supportive communication.

The effect of gregariousness was also unexpected, given that this characteristic, despite a high positive correlation with warmth ( $r=0.594$, see Table 4$)$, was associated with emotionally supportive communication in the opposite direction from warmth. Here again, there is evidence of a suppressor effect. The regression weight of warmth was lower when gregariousness was taken out of the model. Further, the unexpected significance of gregariousness disappears when warmth was taken out of the model (see Table 3, which shows no bivariate correlation in the unexpected direction for gregariousness).

\section{Discussion}

The characteristics that can be observed through direct contact or are documented in the patient file such as sociodemographic variables, chronification, and comorbidity, contributed only slightly to predictability, forcing the physician to specifically identify communication preferences when wanting to take the individual expectations of the CLBP patient into consideration. However, age offers a certain orientation; older patients tended to prefer communication about personal circumstances and to assess open and participatory 


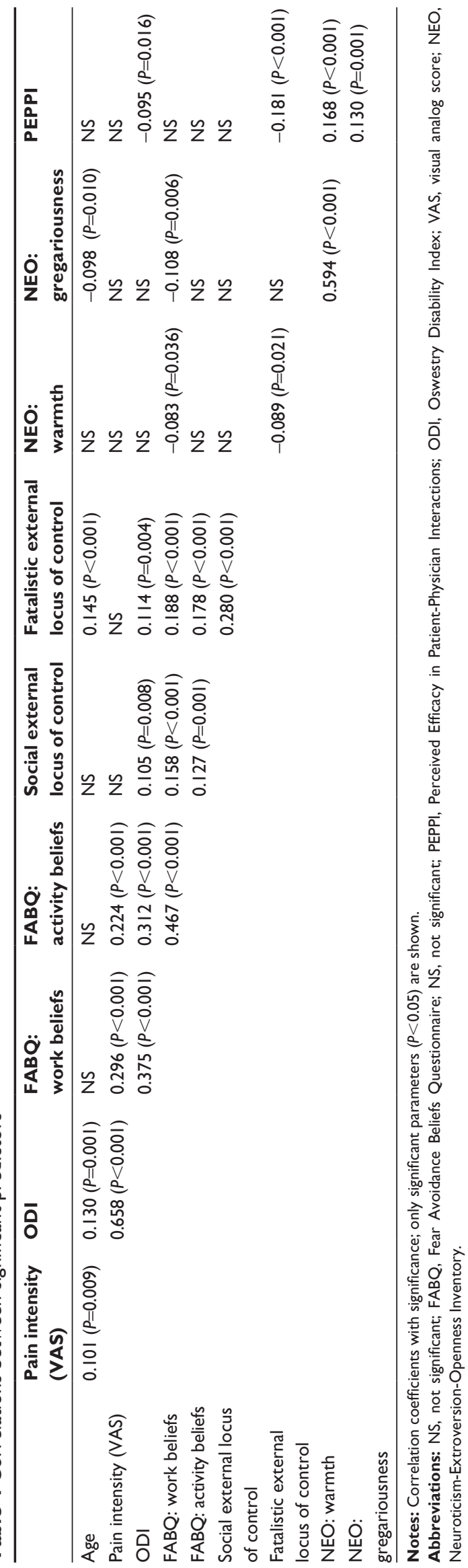

communication as being less important. Younger patients assigning more importance to the physician's participatory communication style has also been reported in other studies $^{10,30,31,33}$ and reviews. ${ }^{52}$ It appears that some older patients still have a perception of the physician-patient relationship as being paternalistic and prefer a physician whose clear instructions convey the impression of competence (see Swenson et al, ${ }^{53}$ who studied the reasons for preferring the traditional communication style in a qualitative study). However, in our sample, the effect of age was small. Even older patients showed a clear preference for the participatory communication style, as demonstrated by the fact that their mean value on the patient participation scale was the second highest of all KOPRA scale means (Table 5).

In contrast with some existing studies, ${ }^{29-31}$ we found no effect of sex. However, the existing studies are not directly comparable with our study, because no homogeneous sample of CLBP patients was examined in the existing literature on predictors of communication preferences. With respect to education and sociodemographic status, other authors have found a correlation with the preference for a participatory communication style ${ }^{10,32,33,54}$ that we could not find in CLBP patients. Also, in contrast with other studies coming to the conclusion that patients who are more seriously ill tend to delegate more responsibility to the physician (see Ende et al ${ }^{55}$ ), in our study, higher pain intensity was associated with greater expectations of patient participation, but also with greater expectations in other areas of communication.

Psychologic factors that influence communication preferences have rarely been studied. In a sample of the normal population, Hashimoto and Fukuhara ${ }^{56}$ found that, even after adjusting sociodemographic variables, an internal locus of control is associated with preference for a participatory communication style. Again, we obtained different results for CLBP patients; in our data, an external locus of control (and participatory communication) was generally associated with higher expectations of the physician's communication behavior. More pronounced fear avoidance beliefs were also a predictor that patients more clearly wanted the behavior measured in the KOPRA questionnaire. In summary, it can be stated that psychologic factors representing risk factors for chronification and lower treatment effects for CLBP patients (see Woby et $\mathrm{al}^{57}$ for external locus of control, and Werneke et $\mathrm{al}^{58}$ and Keeley et $\mathrm{al}^{59}$ for fear avoidance beliefs) also lead to more pronounced expectations of the physician's communicative behavior. A differential effect with differences depending on the area of communication (as proven for age) was not seen here. 
Table 5 KOPRA scale values for three age groups

\begin{tabular}{lllll}
\hline & $\begin{array}{l}\text { Patient participation } \\
\text { and patient orientation }\end{array}$ & $\begin{array}{l}\text { Effective and open } \\
\text { communication }\end{array}$ & $\begin{array}{l}\text { Emotionally supportive } \\
\text { communication }\end{array}$ & $\begin{array}{l}\text { Communication about } \\
\text { personal circumstances }\end{array}$ \\
\hline$\leq 45$ years & $73.6(14.3)$ & $80.7(14.5)$ & $50.3(21.5)$ & $25.1(23.6)$ \\
$45-55$ years & $71.0(15.8)$ & $76.2(15.0)$ & $49.1(20.4)$ & $24.8(21.9)$ \\
$>55$ years & $70.2(14.4)$ & $74.0(15.7)$ & $52.7(19.3)$ & $32.5(22.8)$ \\
\hline
\end{tabular}

Notes: Range for all scales: $0-100$. Higher values stand for more pronounced preferences. Mean and standard deviation are shown. The cutoff values of the age groups are the tertiles of the age distribution.

In addition to the psychologic risk factors of external locus of control and fear avoidance beliefs, the effect of extraversion and self-efficacy in patient-physician interaction was analyzed. As expected, the personality trait of warmth was associated with higher expectations of the physician's communicative behavior, perhaps because the people with high values on the warmth dimension generally value communication and interpersonal contact more highly.

Self-efficacy in patient-physician interaction was always associated with higher expectations of communicative behavior on the part of physicians, without showing great differences between the various areas of communication. We interpret this result as follows. Patients with back pain who have the confidence to ask questions of their physicians and make the most appointments with their physician also expect greater communicative behavior from their physician in all areas. On the other hand, patients who lack confidence when communicating with their physician and do not have great expectations of interaction generally rate the physician's communicative behavior as not so important.

The total explanation of variance in communication preferences by the predictors examined here was not particularly high at $8 \%-19 \%$, and was of the same magnitude as that reached by studies in other groups of chronically ill patients. ${ }^{33,56}$ Since we considered many patient characteristics, it can be assumed that the communication preferences of CLBP patients depend to a great extent on the context of care. This has also been reported for other illnesses in several studies. ${ }^{11,15}$ For example, Vogel et a ${ }^{60}$ found that, for breast cancer patients, preference regarding a participatory communication style remained stable over 6 months in only $50 \%$ of those surveyed.

The fact that our study of CLBP patients regarding the predictors of communication preferences frequently reached conclusions different from those of existing studies for other diagnoses indicates that there are specific influencing factors and that the results obtained from other patient groups cannot necessarily be transferred to pain patients.
The strengths of our study are that we examined a relatively large sample of CLBP patients, defined communication preferences very broadly, and tested many potential predictors of communication preferences in parallel. However, there are several limitations. We did not take context factors (eg, physician sex, previous experience with providers) into account and had a relatively high nonresponder rate of $32.5 \%$. Since we have no detailed information on the nonresponders, it is impossible to estimate what bias this may have caused. Treatment motivation was measured only by the physician and not by the patient.

In addition, it should be noted that we considered only physicians as providers, although many professions are involved in the multidisciplinary treatment of patients with pain. The results presented here can thus be considered valid only for physicians. Finally, despite the many variables measured, some potential influencing factors were not taken into consideration. Psychologic variables omitted include depression ${ }^{61}$ and catastrophizing. ${ }^{62}$ With regard to medical variables, we included no other characteristics of physical pathology aside from pain intensity, comorbidity, and duration of disease. However, there are studies showing that physical pathology has no predictive power after pain intensity has been considered, because its influence is mediated by pain intensity. ${ }^{63}$

\section{Conclusion}

Providers should take into account that CLBP patients have a great need for open communication. This finding raises doubts about recommendations that the physician should use neutral and nonthreatening terms ${ }^{63}$ when communicating with CLBP patients. Many patients also want a participatory communication style. Given that the spread of preferences in this area was rather low, providers can assume with a rather high probability that a patient-centered communication style will meet the needs of their patients. A flexible approach to individual communication needs appears to be especially important for communication about emotional and personal issues, because patients show the clearest differences in these areas. 
The relevance of personal characteristics for predicting communication preferences seems to be limited, given that we achieved a maximum explanation of variance of only $19 \%$, despite considering many sociodemographic, medical, pain-related, and psychologic variables. Therefore, physicians will generally have to gain an idea of the patient's expectations in the respective treatment situation. The results of our study show that, for older patients, a higher preference for a personal communication style and a lower preference for effective, open, and participatory communication can be expected; however, the size of this effect is rather small, and most patients aged over 70 years rate open and patientcentered communication positively.

Providers must consider the fact that those with known psychologic risk factors (eg, fear avoidance beliefs), extroverted patients, and patients who are very self-confident in their interaction with the physician demand the communicative behavior measured with the KOPRA questionnaire to a greater extent, ie, they prefer a physician who simultaneously uses patient-centered and open communication, is emotionally supportive, and occasionally discusses personal circumstances with the patient.

\section{Acknowledgments}

The study was conducted as part of the project "Patient-provider communication for chronically ill patients: gender- and agespecific preferences of patients," funded in Germany by the Federal Ministry of Education and Research (grant 01 GX 0740) as part of the funding priority for "Chronic Illnesses and Patient Orientation" (www.forschung-patientenorientierung.de). Desiree Kosiol was part of the project team for long phases of the project. We would like to thank her for her extremely competent and helpful contribution. We also wish to thank the cooperating rehabilitation centers for their support in data collection: Eisenmoorbad Bad Schmiedeberg (Bad Schmiedeberg), Fachklinikum Brandis (Brandis), Klinik Niederbayern (Bad Füssing), Salztalklinik (Bad Soden-Salmünster), Ambulante Reha-Klinik Sanaris (Passau), Ambulantes Reha Centrum (Schweinfurt), Ambulantes Rehazentrum Wöhrderwiese (Nürnberg), Gesundheitszentrum am Lutherhaus (Essen), REGIO-Reha (Freiburg), REHA-Tagesklinik im Forum Pankow (Berlin), and Gesundheitszentrum Chiemgau (Traunstein). The article processing charge was funded by the open access publication fund of the Albert Ludwigs University Freiburg.

\section{Disclosure}

The authors report no conflicts of interest in this work.

\section{References}

1. Street J, Makoul G, Arora NK, Epstein RM. How does communication heal? Pathways linking clinician-patient communication to health outcomes. Patient Educ Couns. 2009;74:295-301.

2. Zolnierek KBH, DiMatteo MR. Physician communication and patient adherence to treatment: a meta-analysis. Med Care. 2009;47: 826-834.

3. Stewart M, Brown JB, Donner A, et al. The impact of patient-centered care on outcomes. J Fam Pract. 2000;49:796-804.

4. Matthias MS, Bair MJ. The patient-provider relationship in chronic pain management: where do we go from here? Pain Med. 2010;11: 1747-1749.

5. Allegretti A, Borkan J, Reis S, Griffiths F. Paired interviews of shared experiences around chronic low back pain: classic mismatch between patients and their doctors. Fam Pract. 2010;27:676-683.

6. Baker SC, Gallois C, Driedger SM, Santesso N. Communication accommodation and managing musculoskeletal disorders: doctors' and patients' perspectives. Health Commun. 2011;26:379-388.

7. Upshur CC, Bacigalupe G, Luckmann R. "They don't want anything to do with you": patient views of primary care management of chronic pain. Pain Med. 2010;11:1791-1798.

8. Eggly S, Tzelepis A. Relational control in difficult physicianpatient encounters: negotiating treatment for pain. J Health Commun. 2001;6:323-333.

9. Street RL, Krupat E, Bell RA, Kravitz RL, Haidet P. Beliefs about control in the physician-patient relationship: effect on communication in medical encounters. J Gen Intern Med. 2003;18:609-616.

10. Swenson SL, Buell S, Zettler P, White M, Ruston DC, Lo B. Patientcentered communication. Do patients really prefer it? J Gen Intern Med. 2004;19:1069-1079.

11. Epstein RM, Franks P, Fiscella K, et al. Measuring patient-centered communication in patient-physician consultations: theoretical and practical issues. Soc Sci Med. 2005;61:1516-1528.

12. Mallinger JB, Shields CG, Griggs JJ, et al. Stability of decisional role preference over the course of cancer therapy. Psychooncology. 2006;15: 297-305.

13. Taylor K. Paternalism, participation and partnership - the evolution of patient centeredness in the consultation. Patient Educ Couns. 2009;74:150-155.

14. Ishikawa $H$, Hashimoto $H$, Yano E. Patients' preferences for decision making and the feeling of being understood in the medical encounter among patients with rheumatoid arthritis. Arthritis Rheum. 2006;55: 878-883.

15. Jahng KH, Martin LR, Golin CE, DiMatteo MR. Preferences for medical collaboration: patient-physician congruence and patient outcomes. Patient Educ Couns. 2005;57:308-314.

16. Cvengros JA, Christensen AJ, Cunningham C, Hillis SL, Kaboli PJ. Patient preference for and reports of provider behavior: impact of symmetry on patient outcomes. Health Psychol. 2009;28:660-667.

17. Street RL Jr, O’Malley KJ, Cooper LA, Haidet P. Understanding concordance in patient-physician relationships: Personal and ethnic dimensions of shared identity. Ann Fam Med. 2008;6:198-205.

18. Krupat E. Patient-physician fit: an idea whose time has come. Med Decis Making. 2006;26:110-111.

19. Rodin G, Mackay J,Zimmermann C, et al. Clinician-patient communication: a systematic review. Support Care Cancer. 2009;17: 627-644.

20. Say R, Murtagh M, Thomson R. Patients' preference for involvement in medical decision making: a narrative review. Patient Educ Couns. 2006;60:102-114.

21. Levinson W, Kao A, Kuby A, Thisted RA. Not all patients want to participate in decision making. A national study of public preferences. J Gen Intern Med. 2005;20:531-535.

22. Fujimori M, Uchitomi Y. Preferences of cancer patients regarding communication of bad news: a systematic literature review. Jpn J Clin Oncol. 2009;39:201-216.

23. Hall JA, Stein TS, Roter DL, Rieser N. Inaccuracies in physicians' perceptions of their patients. Med Care. 1999;37:1164-1168. 
24. Sobo EJ. Pediatric nurses may misjudge parent communication preferences. J Nurs Care Qual. 2004:253-262.

25. Hudak PL, Frankel RM, Braddock CI, et al. Do patients' communication behaviors provide insight into their preferences for participation in decision making? Med Decis Making. 2008;28:385-393.

26. Farin E, Gramm L, Kosiol D. Development of a questionnaire to assess communication preferences of patients with chronic illness. Patient Educ Couns. 2011;82:81-88.

27. Krupat E, Rosenkranz SL, Yeager CM, Barnard K, Putnam SM, Inui TS. The practice orientations of physicians and patients: the effect of doctor-patient congruence on satisfaction. Patient Educ Couns. 2000;39:49-59.

28. Leckie J, Bull R, Vrij A. The development of a scale to discover outpatients' perceptions of the relative desirability of different elements of doctors' communication behaviours. Patient Educ Couns. 2006;64:69-77.

29. Arora NK, McHorney CA. Patient preferences for medical decision making: who really wants to participate? Med Care. 2000;38:335-341.

30. Krupat E, Yeager CM, Putnam S. Patient role orientations, doctor-patient fit, and visit satisfaction. Psychol Health. 2000;15:707-719.

31. Krupat E, Bell RA, Kravitz RL, Thom D, Azari R. When physicians and patients think alike: patient-centered beliefs and their impact on satisfaction and trust. J Fam Pract. 2001;50:1057-1062.

32. Schneider A, Körner T, Mehring M, Wensing M, Elwyn G, Szecsenyi J. Impact of age, health locus of control and psychological co-morbidity on patients' preferences for shared decision making in general practice. Patient Educ Couns. 2006;61:292-298.

33. Garfield S, Smith F, Francis SA, Chalmers C. Can patients' preferences for involvement in decision-making regarding the use of medicines be predicted? Patient Educ Couns. 2007;66:361-367.

34. Bastiaens H, Van Royen P, Pavlic DR, Raposo V, Baker R. Older people's preferences for involvement in their own care: a qualitative study in primary health care in 11 European countries. Patient Educ Couns. 2007;68:33-42.

35. Longo MF, Cohen DR, Hood K, et al. Involving patients in primary care consultations: assessing preferences using discrete choice experiments. Br J Gen Pract. 2006;56:35-42.

36. Farin E, Gramm L, Schmidt E. Taking into account patients' communication preferences: Instrument development and results in chronic back pain patients. Patient Educ Couns. 2012;86:41-48.

37. Peters E, Lipkus I, Diefenbach MA. The functions of affect in health communications and in the construction of health preferences. J Commun. 2006;56 Suppl:S140-S162.

38. Glattacker M, Meixner K, Farin E, Jäckel WH. [Development and psychometrie testing of a rehabilitation specific comorbidity score]. Physikalische Medizin, Rehabilitationsmedizin, Kurortmedizin. 2007;17:260-270. German.

39. Mannion AF, Junge A, Fairbank CT, Dvorak J, Grob D. Development of a German version of the Oswestry Disability Index. Part 1: cross-cultural adaptation, reliability, and validity. Eur Spine J. 2006;15:55-65.

40. Ostendorf F, Angleitner A. [Revised NEO Personality Inventory]. Göttingen: Hogrefe; 2004. German.

41. Pfingsten M, Kröner-Herwig B, Leibing E, Kronshage U. Validation of the German version of the Fear-Avoidance Beliefs Questionnaire (FABQ). Eur J Pain. 2000;4:259-266.

42. Moss-Morris R, Weinman JA, Petrie KJ, Horne R, Cameron L, Buick DL. The Revised Illness Perception Questionnaire (IPQ-R). Psychol Health. 2002;17:1-16.

43. Glattacker M, Bengel J, Jäckel WH. [German version of the Illness Perception Questionnaire-Revised (IPQ-R): Psychometric evaluation in patients with chronic somatic illness]. Zeitschrift für Gesundheitspsychologie. 2009:17:158-169. German.
44. Lohaus A, Schmitt G-M. Kontrollüberzeugungen zu Krankheit und Gesundheit (KKG), a German test for assessing health-related control beliefs. Diagnostica. 1989;35:59-72. German.

45. Maly RC, Frank JC, Marshall GN, DiMatteo MR, Reuben DB. Perceived efficacy in patient-physician interactions (PEPPI): validation of an instrument in older persons. J Am Geriatr Soc. 1998;46:889-894.

46. Graham JW. Missing data analysis: making it work in the real world. Ann Rev Psychol. 2009;60:549-576.

47. Schafer JL. NORM: multiple imputation of incomplete multivariate data under a normal model, version 2.03, software for Windows 95/98/ NT, 1999. Available from: http://sites.stat.psu.edu/ jls/misoftwa.html. Accessed September 15, 2013.

48. Rubin DB. Multiple Imputation for Nonresponse in Surveys. New York, NY: Wiley; 1987.

49. IBM SPSS 19.0, Armonk, NY: IBM Corporation; 2011.

50. MacKinnon DP, Krull JL, Lockwood CM. Equivalence of the mediation, confounding and suppression effect. Prev Sci. 2000;1: 173-181.

51. Conger AJ. A revised definition for suppressor variables: a guide to their identification and interpretation. Educ Psychol Meas. 1974;34: $35-46$.

52. Hall JA, Roter DL. Do patients talk differently to male and female physicians? A meta-analytic review. Patient Educ Couns. 2002;48: 217-224.

53. Swenson SL, Zettler P, Lo B. 'She gave it her best shot right away': patient experiences of biomedical and patient-centered communication. Patient Educ Couns. 2006;61:200-211.

54. McKinstry B. Do patients wish to be involved in decision making in the consultation? A cross sectional survey with video vignettes. $B M J$. 2000;321:867-871.

55. Ende J, Kazis L, Ash A, Moskowitz M. Measuring patients' desire for autonomy. J Gen Intern Med. 1989;4:23-30.

56. Hashimoto H, Fukuhara S. The influence of locus of control on preferences for information and decision making. Patient Educ Couns. 2004;55:236-240.

57. Woby SR, Watson PJ, Roach NK, Urmston M. Are changes in fearavoidance beliefs, catastrophizing, and appraisals of control, predictive of changes in chronic low back pain and disability? Eur J Pain. 2004;8: 201-210.

58. Werneke MW, Hart DL, George SZ, Stratford PW, Matheson JW, Reyes A. Clinical outcomes for patients classified by fear-avoidance beliefs and centralization phenomenon. Arch Phys Med Rehabil. 2009;90: 768-777.

59. Keeley P, Creed F, Tomenson B, Todd C, Borglin G, Dickens C. Psychosocial predictors of health-related quality of life and health service utilisation in people with chronic low back pain. Pain. 2008;135: 142-150.

60. Vogel BA, Bengel J, Helmes AW. Information and decision making: patients' needs and experiences in the course of breast cancer treatment. Patient Educ Couns. 2008;71:79-85.

61. Pincus TP, Burton AKP, Vogel SD, Field APP. A systematic review of psychological factors as predictors of chronicity/disability in prospective cohorts of low back pain. Spine. 2002;27:E109-E120.

62. Lamé IE, Peters ML, Vlaeyen JWS, Kleef M, Patijn J. Quality of life in chronic pain is more associated with beliefs about pain, than with pain intensity. Eur J Pain. 2005;9:15-24.

63. Zinn C. Doctors told to use positive language in managing pain. BMJ. 2003;326:301. 


\section{Publish your work in this journal}

Patient Preference and Adherence is an international, peer-reviewed, open access journal focusing on the growing importance of patient preference and adherence throughout the therapeutic continuum. Patien satisfaction, acceptability, quality of life, compliance, persistence and their role in developing new therapeutic modalities and compounds to optimize clinical outcomes for existing disease states are major areas of interest. This journal has been accepted for indexing on PubMed Central. The manuscript management system is completely online and includes a very quick and fair peer-review system. Visit http://www.dovepress.com/ testimonials.php to read real quotes from published authors.

\footnotetext{
Submit your manuscript here: http://www.dovepress.com/patient-preference-and-adherence-journal
} 